\title{
Using temporal formalisms to support organizational creativity
}

\author{
Maria Mach-Król \\ Dept. of Business Informatics \\ University of Economics \\ Katowice, Poland \\ maria.mach-krol@ue.katowice.pl
}

\begin{abstract}
The paper is devoted to the question of supporting organizational creativity with temporal logics implemented in intelligent systems. It presents motivation for such a solution, and discusses possible formalisms to be used. The main aim of the paper is to present different application areas in the context of organizational creativity, where temporal logics could be successfully used.
\end{abstract}

\section{Keywords - temporal logic, temporal intelligent system, organizational creativity, creative and situational knowledge}

\section{INTRODUCTION}

Organizational creativity is a relatively new concept in the theory of management, which partially arose on the ground of knowledge management.

There are many definitions of organizational creativity, but it is commonly perceived as a team, dynamic activity, responding to changing features of organization's environment, a team process - see e.g. [1], [2].

The organizational creativity is therefore to be perceived in the context of organizational dynamics, because it depends on the situational changes and is composed of processes. Therefore while discussing the question of computer support for organizational creativity, the temporal aspects may not be omitted.

Such a way of formulating this problem - underlining its dynamic aspect - justifies a proposal of using an intelligent system with a temporal knowledge base, as a tool supporting creation and development of organizational creativity, which is understood as organizational asset (see e.g. [3], [4]).

By the system with a temporal knowledge base we will understand (slightly modifying the definition given in [5]) an artificial intelligence system, which explicitly performs temporal reasoning. Such a system contains not only fact base, rule base, and inference engine, but also directly addresses the question of time. For an intelligent system to be temporal, it should contain explicit time representations in its knowledge base - formalized by the means of temporal logics - and at least in the representation and reasoning layers.

The main aim of the paper is to present the application areas of organizational creativity, where temporal logics could be helpful.

The paper is organized as follows. In section 2 motivation for using temporal logic to support organizational creativity is presented. Section 3 contains some discussion on temporal representation of creative knowledge, and on different application areas within organizational creativity, where temporal reasoning may be used. The next section discusses some proposals of temporal logics that may be successfully used to formalize organizational, creative knowledge. In section 5, the advantages of temporal formalization in the context of organizational creativity are pointed out. The last section contains summary and conclusions.

\section{Motivation}

While discussing the use of any computer tool, one has to take into account first of all the features of the domain to be supported. This applies also to systems with a temporal knowledge base and their application in supporting organizational creativity.

Some elements that justify the use of an intelligent tool with direct time references, may be found in the definitions of organizational creativity:

[6] and [7] claim that the effects of organizational creativity encompass ideas and processes - which in our opinion should be referred to as creative knowledge. The knowledge is to be codified and stored in a knowledge base, and because it is a changing knowledge, the knowledge be should be a temporal one;

In the definition given by [8] the author points out that organizational creativity is more heuristic than algorithmic in nature (p. 33) - therefore it is not possible to use classical analytical tools, because heuristic tasks lack of algorithmic structure, they are complex and uncertain (see e.g. [9] p. 6);

[1] suggests that ideas born during creative processes (that is, the creative knowledge) must be adequate to the situation ( $\mathrm{p}$. 289). Therefore they have to change dynamically, because the situation of organization also constantly changes;

The changeability, dynamics, and process nature of organizational creativity, which justify its codification in a temporal knowledge base, are stressed in definitions given by [10], [11], [12], [13], [14]; 
[2] point out that organizational creativity must be analyzed on individual, group, and organizational levels. This justifies the use of a knowledge base: if the creativity (its effects) is to penetrate between the levels, to support collaboration, a system with a temporal knowledge base enables such penetration;

The justification for using temporal formalisms for codifying of creative knowledge may be found in the definitions given by [15], and [16], where authors point the badly structured nature of creative problems. One of temporal formalisms' advantages is the possibility to formalize unstructured problems.

While reading many authors' discussions on the essence of organizational creativity, one sees that this is primarily team activity. As it has been said above, the effect of this activity may be referred to as "creative knowledge", which itself generates new ideas, concepts, and solutions. To do so, the creative knowledge must be first codified, and next disseminated. This justifies the use of a knowledge base system. But the creative knowledge changes in time, due to several reasons.

First, organizational creativity is a process, therefore its effects are subject to change. Moreover, the process encompasses solving problems that also change, because the organization's environment changes [5] p. 13-15, [17], p. 150, 176.

Second, each knowledge - including the creative one changes simply with the passage of time, with the flow of new information about objects [18].

Third, organizational creativity is linked with dynamics, which can be seen e.g. in the assets approach to this creativity or in the requirement of adapting creative knowledge to situational context.

The assets view of organizational knowledge and creativity the dynamics is expressed by a constant improvement of these assets to keep up with the changes in organizations and their environment - see e.g. [3]. In this way organizations adapt themselves to changes [4]. Such an adaptation occurs in time, therefore organizational creativity is connected with temporality. Moreover, assets must be developed up, therefore organizational creativity and its artifacts are dynamic.

The efforts of capturing assets' dynamics may be seen in such areas, as assets' approach, dynamic econometrics - see e.g. [19] or dynamic economics - see e.g. [20]. But these are solutions aimed only at codification and analysis of quantitative phenomena. Knowledge - including the creative one - is of qualitative nature, therefore to codify, to analyze, and to reason about it qualitative tools are needed. One of such tools is temporal logic, which enables to formalize qualitative knowledge, and also considers time. This tool is used to formalize knowledge in temporal knowledge bases. The detailed discussion on different temporal formalisms may be found e.g. in [18], [21] or [22].
All the above leads to conclusion that a knowledge base system is not enough to support organizational creativity, because classical knowledge bases do not support time. Therefore in this paper we propose the use of a temporal knowledge base system, as defined earlier. Such system is able to perform the tasks arising from the characteristics of organizational creativity and its artifacts..

\section{TEMPORAL REPRESENTATION OF CREATIVE AND SITUATIONAL KNOWLEDGE}

There exists an abundant literature on using temporal logics for knowledge representation and reasoning, not only in intelligent systems with a single knowledge base, but also in distributed systems, agent systems or systems coordinating robots' activities. It may be noticed a similarity between these tasks and the support of organizational creativity, because, generally speaking, it is necessary to:

- represent dynamic knowledge (about the environment),

- represent agents' beliefs (and their change),

- coordinate the functioning of elements in distributed systems.

Similar tasks are linked with supporting organizational creativity: it is necessary to represent creative knowledge and its changes, to represent knowledge about dynamic situation of organization, to coordinate activities of creative processes participants and to enable their communication.

Table I presents a survey of selected applications of temporal logics, together with their reference to organizational creativity. The references illustrate, how it would be possible to transfer concepts from the literature to the system with temporal knowledge base, supporting organizational creativity.

As it can be seen from the above, the use of temporal logics for supporting distributed, team activities is not a new idea. Temporal applications for engineering domain were present already years ago, from the very beginning of research in this area. Only short ago there came up attempts for using this formalization for management, see e.g. [5], [32] and other works by this author. In this paper the novelty lies in the application of temporal formalism - to the organizational creativity and creative knowledge.

The applications of temporal logics enumerated in Table 1 became an inspiration to elaborate a concept of using temporal logics in the intelligent system supporting organizational creativity, because this creativity is a dynamic, team process, that proceeds in the interaction with changeable, unsure organization's environment.

In the context of our proposal, the attention should be paid to the work [33], in which the authors suggest using ontology and temporal logic to model complex activities based on temporal knowledge. The process of organizational creativity is such an activity, and creative knowledge as well as situational 
knowledge are both temporal. In this paper we do not address the question of creative knowledge ontology, but it should be noted that an attempt to create such an ontology and to link it with the selected ontology of time, as well as with a selected temporal formalism, is a very interesting research problem.

TABLE I. SELECTED APPLICATIONS OF TEMPORAL LOGICS.

\begin{tabular}{|c|c|c|}
\hline Author & Application & Reference to organizational creativity \\
\hline$[23]$ & $\begin{array}{l}\text { The use of temporal logic for reasoning about } \\
\text { possible behavior of distributed hybrid systems }\end{array}$ & $\begin{array}{l}\text { Temporal logic as a tool for reasoning about possible } \\
\text { development directions of organizational creativity } \\
\text { and creative knowledge }\end{array}$ \\
\hline [24] & $\begin{array}{l}\text { The use of TPL (Temporal Pattern Logic) } \\
\text { modification named FTPL for dynamic } \\
\text { reconfiguration of system components }\end{array}$ & $\begin{array}{l}\text { Dynamic reconfiguration of creative knowledge sub- } \\
\text { bases }\end{array}$ \\
\hline [25] & $\begin{array}{l}\text { The use of temporal logic for conceptual modeling } \\
\text { of data }\end{array}$ & $\begin{array}{l}\text { The use of temporal logic for conceptual modeling } \\
\text { and representation of creative knowledge }\end{array}$ \\
\hline [26] & $\begin{array}{l}\text { LTL - Linear Temporal Logic used to control } \\
\text { robots in an uncertain environment }\end{array}$ & $\begin{array}{l}\text { The use of temporal logic for formalizing knowledge } \\
\text { about (uncertain) organization's situation }\end{array}$ \\
\hline [27] & $\begin{array}{l}\text { Specifications in temporal logic, to control } \\
\text { probabilistic systems operating in dynamic, } \\
\text { partially known environment }\end{array}$ & $\begin{array}{l}\text { Specifications in temporal logic to control changes } \\
\text { of creative knowledge and knowledge about } \\
\text { organization's situation }\end{array}$ \\
\hline [28] & $\begin{array}{l}\text { The use of incremental temporal logic to control } \\
\text { robots interacting with dynamic agents }\end{array}$ & $\begin{array}{l}\text { Temporal logic as a tool for incremental } \\
\text { representation of dynamic creative knowledge }\end{array}$ \\
\hline [29] & $\begin{array}{l}\text { Axioms of temporal logic used to self-control of } \\
\text { logical agents }\end{array}$ & $\begin{array}{l}\text { Temporal logic used to control changes of creative } \\
\text { knowledge sub-bases }\end{array}$ \\
\hline [30] & $\begin{array}{l}\text { Approach arising from LTL to synthesize } \\
\text { communication strategies, and control strategies } \\
\text { in a robots' team, depending on the environment }\end{array}$ & $\begin{array}{l}\text { The use of temporal logic to drive the } \\
\text { communication of a team in an organizational } \\
\text { creativity process, and/or the use of temporal logic to } \\
\text { drive the communication with a system with a } \\
\text { temporal knowledge base }\end{array}$ \\
\hline [31] & $\begin{array}{l}\text { Control of dynamic systems with the use of } \\
\text { temporal logic }\end{array}$ & $\begin{array}{l}\text { Temporal logic as a tool for manipulating knowledge } \\
\text { in an intelligent system }\end{array}$ \\
\hline
\end{tabular}

\section{PROPOSALS OF TEMPORAL FORMALIZATION FOR ORGANIZATIONAL CREATIVITY}

In the literature there are proposals of using very different temporal logics. In our paper we propose to use - in order to represent creative and situational knowledge - the situation calculus (and the programming language Golog, aimed at implementing programs written in situation calculus). The reasons for choosing this formalism are as follows:

- Situation calculus is a formalism for describing dynamic knowledge [34],

- Situation calculus has been successfully used to describe agents' collaboration [35].

The most often proposals of using situation calculus concern technical domain - e.g. inference on qualitative information in order to control robots [36], beliefs change of robots [37], [38] - the second work contains also a description of application performing tasks of changing the beliefs; change of agents' beliefs with incomplete or imprecise knowledge about the

This paper has been supported by a grant: „Methodology for Computer Supported Organizational Creativity" from National Science Centre in Poland, 2013/09B/HS4/00473. environment [39]. These are proposals that may inspire the use of situation calculus in a temporal intelligent system supporting organizational creativity. But a special attention should be paid to the work [40], in which the authors propose to use situation calculus to support agents' collaboration, where ,agents” are teams of employees in an organization, created to exchange knowledge and intellectual assets while performing complex tasks. Therefore the situation calculus may be used in a system with temporal knowledge base, supporting the process of organizational creativity.

The situation calculus has been proposed by J. McCarthy in the sixties [41], and further developed by this author together with P. Hayes [42].

The situation calculus is a second order logic, aimed at describing dynamically changing world. Every possible world history is a path of succeeding situations. A special situation is situation denoted $\mathrm{S}_{0}$, so-called initial situation, in which no changes have occurred yet. Every next situation results from performing some actions. Formally speaking, do(a, s) denotes a situation that occurs after performing action a in the situation $\mathrm{s}$. Therefore actions cause changes in the world. Each action has 
preconditions - conditions that must be fulfilled if the action is to be performed. Formally, action precondition is a sentence of the form:

$$
\operatorname{Poss}\left(\mathrm{A}\left(\mathrm{x}_{1}, \ldots, \mathrm{x}_{\mathrm{n}}\right), \mathrm{s}\right) \equiv \Pi_{\mathrm{A}}\left(\mathrm{x}_{1}, \ldots, \mathrm{x}_{\mathrm{n}}, \mathrm{s}\right)
$$

Where:

\section{A - n-ary function symbol,}

$\Pi_{\mathrm{A}}-\mathrm{a}$ formula uniform in $\mathrm{s}$, with free variables form within $\mathrm{x}_{1}, \ldots, \mathrm{x}_{\mathrm{n}}, \mathrm{s}$.

The causal laws are expressed using the so-called effect axioms. Another group of important axioms are the frame axioms, indispensable for establishing, which features remain unchanged independently of performing a given action. The name of these axioms comes from the commonly known problem in the temporal community - namely the frame problem - see e.g. [43], [44], [45]. As the number of frame axioms is generally infinite (because there is an infinite number of features in the world, which remain unaffected by an action), newer approaches propose to use so-called successor state axioms, which describe direct effects of actions much more precisely [34]. Formally, a successor state axiom for $(n+1)$-ary relational fluent $\mathrm{F}$ is a sentence of the form:

$$
\mathrm{F}\left(\mathrm{x}_{1}, \ldots, \mathrm{x}_{\mathrm{n}}, \operatorname{do}(\mathrm{a}, \mathrm{s})\right) \equiv \Phi_{\mathrm{F}}\left(\mathrm{x}_{1}, \ldots, \mathrm{x}_{\mathrm{n}}, \mathrm{a}, \mathrm{s}\right)
$$

Where $\Phi_{\mathrm{F}}\left(\mathrm{x}_{1}, \ldots, \mathrm{x}_{\mathrm{n}}, \mathrm{a}, \mathrm{s}\right)$ is a formula uniform in $\mathrm{s}$.

A successor state axiom for $(n+1)$-ary functional fluent $\mathrm{f}$ is a sentence of the form:

$$
\mathrm{f}\left(\mathrm{x}_{1}, \ldots, \mathrm{x}_{\mathrm{n}}, \operatorname{do}(\mathrm{a}, \mathrm{s})\right)=\mathrm{y} \equiv \Phi_{\mathrm{f}}\left(\mathrm{x}_{1}, \ldots, \mathrm{x}_{\mathrm{n}}, \mathrm{y}, \mathrm{a}, \mathrm{s}\right)
$$

where $\Phi_{\mathrm{f}}$ is a formula uniform in $\mathrm{s}$.

An important feature of the situation calculus in the context of supporting organizational creativity is the possibility to formulate statements concerning causality. This calculus has been used by Reiter to describe changes in a database [34], it also was the basis for many other logical solutions.

The detailed description of the situation calculus, and its formalization may be found e.g. in [34] or [35]

It is an open question whether while deploying a system with a temporal knowledge base the situation calculus will be the only sufficient formalization, or whether it will be necessary to use its extended version, namely temporal situation calculus. The original situation calculus is a so-called action language, aimed at formalizing actions and their effects, treating actions as primary causes of changes in the world. In [46] the author introduced an extension to the situation calculus, expressing time directly. He claimed that introducing the actual time line to the situation calculus, enables specification of behavior rules ( $p$. 52), and this would make easy formalization of creative knowledge. The solution to this dilemma will be possible during the planned practical research.

\section{ADVANTAGES OF TEMPORAL FORMALIZATION IN THE CONTEXT OF ORGANIZATIONAL CREATIVITY}

Summing up the above discussion, the advantages of temporal formalization in an intelligent system supporting organizational creativity should be stressed.

Using temporal representation is well motivated, there are a lot of theoretic works on temporal formalisms and their features, also temporal formalisms have been used in many domains. It is certain, that temporal representation of a domain - including organizational knowledge - has many advantages. They can be divided into several groups:

a) Basic advantages - concerning temporal representation itself, independently from where it is used; these basic advantages also are the origin of advantages from other groups;

b) Advantages concerning representation of change;

c) Advantages concerning representation of causal relationships.

Time, as a dimension, is a basis for reasoning about action and change - only a proper use of temporal dimension allows for representation of change and its features, as e.g. its scope or interactions caused by change [47]. Such explicit temporal reference is possible through the use of a temporal formalism, where time is a basic variable. Moreover, time may be treated in different ways, e.g. may have several different structures, which is necessary in more complex reasoning tasks, e.g. creative ones. The advantages of non-standard time representation, e.g. branching time, and its application for managerial tasks, are presented in [48], and organization of a creative process is one of managerial tasks.

Temporal logic allows encoding both qualitative and quantitative temporal information, as well as relationships among events during the creative process, therefore it is easy to express such relations, as "shorter", "longer", "simultaneously", "earlier" etc. This in turn implies easiness of arranging phenomena in time, even if they overlap - Allen's interval algebra is an example of a formalism which allows such arrangements.

Temporal formalization makes possible to encode discrete and dense changes (according to a model of time adopted), allows for describing change as a process, and for reasoning about causes, effects and directions of change, e.g. changes of creative ideas or in the creative domain itself.

As time is the fourth dimension of the world, it may not be omitted during the reasoning process; otherwise the perspective of analysis would be too narrowed. The temporal dimension allows the organizational creativity support system to "learn": the system collects cases concerning e.g. ideas (or the creative domain) being represented, traces their evolution and thanks to this is able to generate new solutions. 
It has been already said that temporal representation makes possible to represent change as a process. It is so, because with temporal logic, processes can be modeled explicitly - therefore knowledge on their temporal aspect, their interactions, on concurrent processes is easily expressed [49]. Models of processes are useful for describing dense phenomena, as for example economic ones.

Temporal logic gives us richer - temporal aspect included formalization of domain knowledge, it also gives us "knowledge on knowledge": combining temporal operators with formal knowledge representation one can formulate assertions about creative knowledge evolution in a system. Van Benthem presents an example of such combination, suggesting combining temporal and epistemic logic [18], p. 335. Placing creative knowledge in time treated as a basic dimension, one can add new creative knowledge to a base, not removing the "old" one, and with no risk of inconsistencies. Temporal logic, as a knowledge representation language, should provide both explicit knowledge and access to tacit one. Temporal logic, which has reasoning rules built in, is able to provide this property.

Summing up, it should be pointed out that temporal formalisms meet the requirements of knowledge representation in artificial intelligence, such as:

- expressing imprecise and unsure knowledge,

- expressing "relations" of knowledge (e.g. A occurred before B", that very often have no explicit dates;

- different reasoning granulations,

- modeling of persistence.

TABLE II. ADVANTAGES OF TEMPORAL FORMALIZATION IN DIFFERENT ASPECTS OF ORGANIZATIONAL CREATIVITY.

\begin{tabular}{|c|c|}
\hline Aspect (application) & Advantages \\
\hline General & $\begin{array}{l}\text { explicit temporal references: time as a basic notion, } \\
\text { formalization of alternative states during creative process, } \\
\text { representation of changes in relations between creative features/objects, } \\
\text { representation of qualitative and quantitative information and temporal relations in creative } \\
\text { knowledge } \\
\text { easy representation of overlapping events in the creative process, } \\
\text { history of features, events, objects, relations in the creative knowledge }\end{array}$ \\
\hline Knowledge base & $\begin{array}{l}\text { representation of creative beliefs, } \\
\text { explicit modeling of creative processes, } \\
\text { persistence modeling, } \\
\text { "knowledge about creative knowledge", } \\
\text { Access to tacit creative knowledge, } \\
\text { No contradictions between old and new creative knowledge }\end{array}$ \\
\hline Representation of changes & $\begin{array}{l}\text { Discrete and continuous changes in the creative domain, } \\
\text { Description of changes as a process, } \\
\text { Reasoning about reasons, effects and directions of changes in the creative domain }\end{array}$ \\
\hline $\begin{array}{c}\text { Representation of causal } \\
\text { relationships }\end{array}$ & $\begin{array}{l}\text { Easy description of causal relationships in the creative domain } \\
\text { Retro- and proactive events, } \\
\text { "if-then" analysis of creative ideas }\end{array}$ \\
\hline Reasoning & $\begin{array}{l}\text { "learning" of the organizational creativity support system, } \\
\text { Tracing creative features' evolution, } \\
\text { Reasoning about dynamic aspects of creative phenomena, } \\
\text { Reasoning about sequences of events in the organizational creativity support system, } \\
\text { The notion of "possibility", } \\
\text { Qualitative reasoning about creative domain, } \\
\text { Simulation of human commonsense and creative reasoning }\end{array}$ \\
\hline
\end{tabular}

The above postulates are met e.g. by Allen's interval algebra [49]. Therefore enriching an organizational creativity support system with temporal formalisms would allow for taking into account the temporal dimension of creative knowledge, its changes and evolution/development. In this way the creative knowledge, and organizational creativity processes may be managed more effectively. Advantages of temporal formalization in different areas of organizational creativity are presented in Table II.
The research conducted by [50] lets us formulate the postulates for a temporal logic, used to represent creative and situational knowledge. Taking into account the anthropocentric approach proposed by Kalczynski and Chou, one may state the following:

a) It is not important whether the formalism comes from $1^{\text {st }}$ order predicate logic or from modal logic,

b) Formalisms based on change (e.g. situation calculus and its mutations) are closer to human reasoning about time, than formalisms based on time, 
c) Basic temporal entities are not important - using time points or intervals or both to represent creative domain will depend on particular needs - e.g. people during the creative process do not analyze economic texts in the context of temporal entities,

d) Representation of knowledge should be based on qualitative or mixed approaches; the quantitative approach may be considered a special case of the qualitative one - every numeric feature can be represented in a qualitative manner.

Summing up, while choosing the temporal logic to represent creative and situational knowledge, one should first of all consider the way humans perceive temporal aspects of the world. The possibilities of particular temporal logics are less important. In this way the knowledge representation - close to human perception - will enable a more understandable temporal reasoning in the intelligent system.

\section{CONCLUDING REMARKS}

The main aim of this paper was to discuss the possibility of supporting organizational creativity with temporal reasoning. To do this, one should consider a system with temporal knowledge base, formalized in a selected temporal logic or logics.

The use of temporal formalization is justified, as organizational creativity is a dynamic process, moreover, the "product" of this process - namely creative knowledge - is also dynamic. The creative knowledge is of qualitative nature, therefore using temporal logics seems natural, as these formalisms are dedicated and elaborated to represent qualitative phenomena, and their change in time.

We have pointed out several application domains within the context of organizational creativity, where temporal logics may be used. We also proposed to choose the situation calculus or its temporal extension. Of course this is not the only possible choice. As organizational creativity is strictly connected with commonsense reasoning, one may consider also choosing the event calculus [51]. The choice of a formalism to be implemented in a temporal intelligent system will be the subject of future research.

The main research in the future will concern a conceptual model of a temporal intelligent system for organizational creativity support. We also plan to encode some portion of a creative knowledge in a temporal formalism, and check whether temporal reasoning on such encoded knowledge is possible.

\section{REFERENCES}

[1] K. L. Unsworth, „Unpacking Creativity,” Academy of Management Review, Vol. 26, No. 2, pp. 286-297, 2001.

[2] C. Andriopoulos and P. Dawson, Managing Change, Creativity and Innovation. Second Edition, Los Angeles/London/New Delhi/Singapore/Washington DC: SAGE Publications, 2014.
[3] R. Krupski, ed., Rozwój szkoły zasobowej zarządzania strategicznego, Wałbrzych: Wałbrz.Wyż.Szk.Zarz. i Przedsięb., 2011.

[4] D. G. Sirmon, M. A. Hitt, R. D. Ireland and B. A. Gilbert, „Resource Orchestration to Create Competitive Advantage: Breadth, Depth, and Life Cycle Effects," Journal of Management, Vol. 37, No. 5, pp. 13901412, September 2011.

[5] M. A. Mach, Temporalna analiza otoczenia przedsiębiorstwa. Techniki i narzędzia inteligentne, Wrocław: Wydawnictwo AE, 2007.

[6] R. W. Woodman, J. E. Sawyer and R. W. Griffin, ,,Toward a Theory of Organizational Creativity," The Academy of Management Review, Vol. 18, No. 2, pp. 293-321, April 1993.

[7] C. E. Shalley, L. L. Gilson and T. C. Blum, „Matching Creativity Requirements and the Work Environment: Effects on Satisfaction and Intentions to Leave," Academy of Management Journal, Vol. 43, No. 2, pp. 215-223, 1 April 2000.

[8] T. M. Amabile, Creativity in Context: Update to The Social Psychology of Creativity, Boulder: Westview Press, 1996.

[9] A. Aggarwal, „A Taxonomy of Sequential Decision Support Systems,” In: Proc. IS-2001: 4th Annual Informing Science Conference, Kraków, 2001.

[10] E. C. Martins and F. Terblanche, „Building organisational culture that stimulates creativity and innovation," European Journal of Innovation Management, Vol. 6, No. 1, pp. 64 - 74, February 2003.

[11] L. D. Alvarado, „The creative organizations as living systems,” In: Understanding and evaluating creativity, S. Torre and V. Violant, eds., Malaga, Editiones Algiba, 2006, pp. 375-382.

[12] G. Hirst, D. v. Knippenberg and J. Zhou, ,A Cross-Level Perspective on Employee Creativity: Goal Orientation, Team Learning Behavior, and Individual Creativity," Academy of Management Journal, Vol. 52, No. 2, pp. 280-293, 1 April 2009.

[13] M. Baer, „Putting Creativity to Work: The Implementation of Creative Ideas in Organizations," Academy of Management Journal, Vol. 55, No. 1, pp. 1102-1119, 1 October 2012.

[14] M. Basadur, T. Basadur and G. Licina, „Organizational Development,” In: Handbook of Organizational Creativity, M. D. Mumford, ed., London/Waltham/San Diego, Elsevier Inc., 2012, pp. 667-703.

[15] M. D. Mumford, I. C. Robledo and K. S. Hester, „Creativity, Innovation and Leadership: Models and Findings," In: The SAGE Handbook of Leadership , A. Bryman, D. Collinson, K. Grint, B. Jackson and M. UhlBien, eds., London, SAGE Publications Ltd., 2011, pp. 405-421.

[16] M. D. Mumford, K. E. Medeiros and P. J. Partlow, „Creative Thinking: Processes, Strategies, and Knowledge," The Journal of Creative Behavior, Vol. 46, No. 1, pp. 30-47, March 2012.

[17] S. Czaja, Czas w ekonomii. Sposoby interpretacji czasu w teorii ekonomii i w praktyce gospodarczej, Wrocław: Wydawnictwo Uniwersytetu Ekonomicznego, 2011.

[18] J. van Benthem, ,Temporal Logic,” In: Handbook of Logic in Artificial Intelligence and Logic Programming. Volume 4: Epistemic and Temporal Reasoning, D. M. Gabbay, C. J. Hogger and J. A. Robinson, eds., Oxford, Clarendon Press, 1995, pp. 241-350.

[19] J. Jakubczyc, Wprowadzenie do ekonometrii dynamicznej, WarszawaWrocław: Wydawnictwo Naukowe PWN, 1996.

[20] J. Adda and R. Cooper, Dynamic Economics. Quantitative Methods and Applications, Cambridge, Mass.: The MIT Press, 2003.

[21] R. Klimek, Wprowadzenie do logiki temporalnej, Kraków: Uczelniane Wydawnictwa Naukowo-Dydaktyczne AGH, 1999. 
[22] M. Fisher, D. Gabbay and L. Vila, eds., Handbook of Temporal Reasoning in Artificial Intelligence, Amsterdam-Boston-Heidelberg: Elsevier B.V., 2005.

[23] P. Hou and H. Zheng, „Quantified Differential Temporal Dynamic Logic for Verifying Properties of Distibuted Hybrid Systems," In: Logical Foundations of Computer Science, LNCS Vol. 7734, S. Artemov and A. Nerode, eds., Berlin-Heidelberg, Springer, 2013, pp. 234-251.

[24] J. Dormoy, O. Kouchnarenko and A. Lanoix, „Using Temporal Logic for Dynamic Reconfiguration of Components," In: 7th International Conference on Formal Aspects of Component Software, BerlinHeidelberg, 2012.

[25] A. Artale, R. Kontchakov, F. Wolter and M. Zakharyaschev, „Temporal Description Logic for Ontology-Based Data Access," In: Proceedings of the Twenty-Third International Joint Conference on Artificial Intelligence, Beijing, 2013.

[26] S. C. Livingston, R. M. Murray and J. Burdick, „Backtracking temporal logic synthesis for uncertain environments," In: Proc. ICRA-12: International Conference on Robotics and Automation, Saint Paul, MN, 2012

[27] T. Wongpiromsarn and E. Frazzoli, „Control of Probabilistic Systems under Dynamic, Partially Known Environments with Temporal Logic Specifications," In: 51st Annual Conference on Decision and Control, Maui, HI, 2012

[28] T. Wongpiromsarn, A. Ulusoy, C. Belta, E. Frazzoli and D. Rus, „Incremental Temporal Logic Synthesis of Control Policies for Robots Interacting with Dynamic Agents," In: IEEE/RSJ International Conference on Intelligent Robots and Systems, 2012.

[29] S. Constantini, „Self-checking Logical Agents (Extended Abstract), In: Proceedings of the 12th International Conference on Autonomous Agents and Multiagent Systems, Saint Paul, MI, 2013.

[30] Y. Chen, X. Ding, A. Stefanescu and C. Belta, „A Formal Approach to Deployment of Robotic Teams in an Urban-Like Environment," In: Distributed Autonomous Robotic Systems, Springer Tracts in Advanced Robotics 83, A. Martinoli, F. Mondada, N. Correll, G. Mermoud, M. Egerstedt, M. Hsieh, L. Parker and K. Stoy, eds., Berlin Heidelberg, Springer, 2013, pp. 313-327.

[31] E. Wolff, U. Topcu and R. Murray, „Robust Control of Uncertain Markov Decision Processes with Temporal Logic Specifications," In: IEEE Conference on Decision and Control, Grand Wailea, Maui, Hawaii, 2012.

[32] M. Mach-Król, „Prospects of Using Temporal Logics for Knowledge Management," In: Advances in Business ICT, M. Mach-Król and T. Pełech-Pilichowski, eds., Heidelberg, Springer, 2014, pp. 41-52.

[33] G. Okeyo, L. Chen, H. Wang and R. Sterritt, „A Hybrid Ontological and Temporal Approach for Composite Activity Modelling," In: 11th International Conference on Trust, Security, and Privacy in Computing and Communications, Liverpool, 2012.

[34] R. Reiter, Knowledge in Action: Logical Foundations for Specifying and Implementing Dynamical Systems, Cambridge, MA: MIT Press, 2001.
[35] J. Claßen, „Planning and Verification in the Agent Language Golog,” Aachen University: doctoral dissertation, Aachen, 2013.

[36] S. Schiffer, A. Ferrein and G. Lakemeyer, ,Reasoning with Qualitative Positional Information for Domestic Domains in the Situation Calculus," Journal of Intelligent and Robotic Systems, Vol. 66, No. 1-2, pp. 273-300, April 2012.

[37] V. Belle and H. Levesque, ,,Reasoning about Continuous Uncertainty in the Situation Calculus," In: Proceedings of the Twenty-Third International Joint Conference on Artificial Intelligence, Beijing, China, 2013.

[38] M. Pagnucco, D. Rajaratnam, H. Strass and M. Thielscher, „Implementing Belief Change in the Situation Calculus and an Application," In: Logic Programming and Nonmonotonic Reasoning, P. Cabalar and T. Son, eds., Berlin Heidelberg, Springer LNCS 8148, 2013, pp. 439-451.

[39] J. Delgrande and H. Levesque, „Belief Revision with Sensing and Fallible Actions," In: Thirteenth International Conference on Principles of Knowledge Representation and Reasoning, 2012.

[40] A. Toniolo, T. J. Norman, K. Sycara and J. H. Farrington, „Agent Support for Collaboration in Complex Deliberative Dialogues.(Extended Abstract-PhD Thesis), " IFAAMAS.org, 2012.

[41] J. McCarthy, „Situations, actions and causal laws,” In: Semantic Information Processing, M. Minsky, ed., Cambridge, Mass., MIT Press, 1968, pp. 410-417

[42] J. McCarthy and P. Hayes, „Some philosophical problems from the standpoint of artificial intelligence," Machine Intelligence, Vol. 4, pp. 463-502, 1969

[43] P. Hayes, The Frame Problem and Related Problems on Artificial Intelligence, Stanford: Stanford University, 1971.

[44] Y. Xu and P. Wang, ,The frame problem, the relevance problem, and a package solution to both," Synthese, Vol. 187, No. 1, pp. 43-72, 2012.

[45] A. Zambak, „The Frame Problem,” In: Philosophy and Theory of Artificial Intelligence, V. Müller, ed., Berlin Heidelberg, Springer, 2013, pp. 307-319.

[46] J. Pinto, „Temporal reasoning in the situation calculus,” University of Toronto: doctoral dissertation, Toronto, 1994.

[47] L. Vila, „Formal Theories of Time and Temporal Incidence,” In: Handbook of Temporal Reasoning in Artificial Intelligence, M. Fisher, D. Gabbay and L. Vila, eds., Amsterdam, Elsevier, 2005, pp. 1-24.

[48] M. Mach-Król, „Nonlinear Time Ontology for Economic Reality Description," In: The 6th International Conference on Information Technology, Amman, 2013.

[49] J. Allen, „Towards a General Theory of Action and Time,” Artificial Intelligence, Vol. 23, No. 2, 1984

[50] P. Kalczynski and A. Chou, ,Temporal Document Retrieval Model for Business News Archives," Information Processing \& Management, Vol. 41, No. 3, pp. 635-650, 2005

[51] E. T. Mueller, Commonsense Reasoning, San Francisco: Morgan Kaufmann/Elsevier, 2006. 